\title{
Determination of Iron, Zinc, Manganese and Copper Trace Elements in Traditional and Commercial Black Table Olives
}

\section{ISSN: 2640-9208}

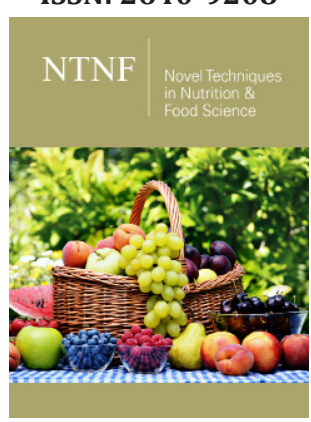

*Corresponding author: Parisa Sadighara, Department of Environmental Health, Food Safety Division, School of Public Health, Tehran University of Medical Sciences, Tehran, Iran

Submission: 侮 June 23, 2021

Published: 眥July 19, 2021

Volume 6 - Issue 1

How to cite this article: Mahsa Alikord, Mohadeseh Pirhadi, Parisa Sadighara. Determination of Iron,Zinc, Manganese and Copper Trace Elements in Traditional and Commercial Black Table Olives. Nov Tech Nutri Food Sci. 6(1). NTNF. 000630. 2021. DOI: 10.31031/NTNF.2021.06.000630

Copyright@ Parisa Sadighara. This article is distributed under the terms of the Creative Commons Attribution 4.0 International License, which permits unrestricted use and redistribution provided that the original author and source are credited.

\section{Mahsa Alikord, Mohadeseh Pirhadi and Parisa Sadighara*}

Department of Environmental Health, Food Safety Division, School of Public Health, Tehran University of Medical Sciences, Tehran, Iran

\begin{abstract}
An Inductively coupled plasma atomic emission spectroscopy method was employed to quantify residues of copper ( $\mathrm{Cu}$ ), iron (Fe), zinc (Zn), and manganese (Mn) in black table olive fruit. Traditional/industrial canned olives were collected from Zanjan, Shiraz and Rudbar, in Iran. The limits of detection were 0.306 , $0.27,0.16$, and $0.46 \mu \mathrm{g} / \mathrm{kg}$, and limit of quantification were $0.918,0.81,0.48$, and $1.38 \mu \mathrm{g} / \mathrm{kg}$, respectively. The accuracy was evaluated and the recoveries being $96.88 \%$ for all of according to the standard addition's method. Therefore, although the concentration of the four metals considered are within safe limits, table olives consumption in diet may be to pose a risk for different population groups in terms of these considered metals.
\end{abstract}

Keywords: Traditional; Industrial; Table olives; Iron; Copper; Zinc; Manganese

\section{Introduction}

Olive (Olea europaea L.) originates in the eastern part of the Mediterranean countries [1]. Olive fruits are applied for olive oil by extraction and also as table olives after maturation and fermentation. The main components of olives including water, lipids, reducing sugars, and phenolic substances are $60-75 \%, 10-25 \%, 2-5 \%$, and 1-3\%. Besides, olives are high in tocopherols, carotenoids, and minerals [1,2]. Olives are also a good source of unsaturated fatty acids [3]. Processing olives to table olives involves removing the bitter taste (oleuropein) as well as subsequent fermentation. Fermentation is one of the first technologies for food processing preservation. To remove its bitterness and increase its shelf life, fermentation is used either with or without heat treatment and with or without the addition of preservatives as well as is packaged with or without a covering liquid. Commercial preparations are usually employed by Spanish-style green olives, California-style ripe olives, and Greek-style black olives that are produced refined green olives, olives darkened by oxidation (ripe olives), and natural olives (mostly black), respectively [4]. The fermentation time depends on some properties such as the ambient temperature, olive type, the fruits ripeness, the salt concentration and $\mathrm{pH}$ [5]. In the natural fermentation, sodium chloride $(\mathrm{NaCl})$ is used as a solution or dry salt, the $\mathrm{pH}$ of the olives decreases and loses their color [6]. In this case, the olives are placed in $\mathrm{NaCl}$ brine without any irritating treatment, thus oleuropein is released from the mesocarp into the brine as well as through acid hydrolysis. Fermentation is also somewhat different, as the lactic acid bacteria is formed in Spanish-processed olive saltwater, while fermentation yeasts are found mainly in Greek light olive brine. The rate of fermentation increases when the growing conditions are favorable for the fermentation of microorganisms [4]. In the Spanish-style green olives and California-style ripe olives, complete removal of the bitter oleuropein composition occurs in a short time by hydrolysis with sodium hydroxide $(\mathrm{NaOH})(1.5-2 \%)$. Also, some chemicals such as iron gluconate (II) or iron lactate (II) are added to stabilize the black color of the olive. 
These methods may also affect the mineral and metallic content of olives which may cause changes in the quality of olives and be attributed to types, location, environment, processing method, packaging materials and chemical additives $[4,7,8]$. The metallic content of food is important in terms of food toxicology because the diet is considered as the main supplier of elements to the body [9]. In addition to the toxicological properties of metallic content, the presence of transfer metals in lipid matrices can adversely affect organoleptic and nutritional properties [7]. Some metals, such as copper $(\mathrm{Cu})$ and zinc $(\mathrm{Zn})$ are considered micronutrients and are essential for human health, that they are consumed in the range of 15-30 and $12-15 \mathrm{mg} /$ day $\mathrm{Cu}$ and $\mathrm{Zn}$, respectively. As the increase in $\mathrm{Cu}$ in the body can cause liver damage and also, Zinc can also interfere with your body's ability to absorb $\mathrm{Cu}$, potentially leading to a deficiency in this key mineral over time [10].

Table olives are the eminent fermented food and there are two types of table olives, which include traditional and commercial olives In Iran. The basis of both methods is the same, but only the final stage pasteurization, as well as the use of food additives are different. In traditional olives, producers do not observe the maximum limit permit. Therefore, this study designed to assess the content of iron, copper, zinc, and magnesium in traditional and commercial olives in Iran in 2019.

\section{Materials and Methods}

\section{Chemicals and Reagents}

The solution of nitric acid $(65 \%(\mathrm{v} / \mathrm{v}))$ and hydrogen peroxide (30\% (v/v)) from Merck Company (Darmstadt, Germany) were analytically prepared and all solutions were prepared with deionized water (DW). EMD Millipore-1.09480 Multielement standard solution was used from Merck Millipore (Darmstadt, Germany). Stock standard solutions for the analyzed elements (1000 $\mathrm{mg} \mathrm{L}^{-1}$, Merck, Darmstadt, Germany) were used to prepare the calibration standards.

\section{Sampling and analytical procedure}

The traditional olive samples were from Rudbar $(n=20)$, Zanjan ( $n=8)$, Shiraz (n=8), and Tehran ( $n=8)$ cities, Iran in 2019. Commercial samples were purchased from the consumer market $(\mathrm{n}=24)$. Measurements of 4 trace metals $(\mathrm{Cu}, \mathrm{Fe}, \mathrm{Mn}$, and $\mathrm{Zn})$ in samples were analyzed. The core of the olives was separated with a plastic tools (no effect on the number of metals) that had been before washed with DW and nitric acid. The remaining materials (pulp) was dehydrated in an oven at $90-100{ }^{\circ} \mathrm{C}$ for $72 \mathrm{~h}$. The ashes left in the container were kept in bags in the refrigerator. Acid digestion in microwave was applied for analyses. $2 \mathrm{~g}$ of sample was poured into vessels of microwave system. $10 \mathrm{~mL}$ of mix with nitric acid and hydrogen peroxide with rate of 8:2, v/v was added. Then mix was well shaken and kept in $25^{\circ} \mathrm{C}$ for $10 \mathrm{~min}$. After that, the mix boiled on a hotplate at $130{ }^{\circ} \mathrm{C}$ for $4 \mathrm{~h}$ until digestion was complete. At the end of the decomposition, the digested samples were left to cool until room temperature and then the solution was filtered using filter paper No. 42 . The filtrate was diluted with DW to final volume of $10 \mathrm{ml}$. All samples were kept into refrigerator until injection to ICP-OES instrument [11]. Analysis of each sample was measured three times.

\section{Operating conditions of ICP-OES instrumental}

All samples were analyzed using ICP-OES bottles for analysis. Condition of ICP-OES Instrument (Spectro Arcos, SPECTRO, Germany) with EOP torch type (flared end Torch of EOP 2.5mm). RF generator power was 1400W, Resonance frequency 27.12, Argon gas (grade 6) applied for Plasma, auxiliary, and nebulizer gas. Flow of plasma gas, flow of auxiliary gas, and flow of nebulizer gas were 14.50, 0.90 and $0.85\left(\mathrm{Lmin}^{-1}\right)$, respectively. Afterwards, time of sample uptake, time of rinse, time of initial stabilization, reflash and total injection time was $45 \mathrm{~s}, 45 \mathrm{~s}$ and 240 s respectively, time of delay and time of between replicate analyses were zero. The measurement was conducted three times, the generator frequency of RF was 27.12MHz (resonance frequency). Type of detector solid state and chamber of spry was CCD and Cyclonic, Modified Lichte, respectively. Type of sample delivery pump was four-channel, software controlled; peristaltic pump enables exact sample flows. Prewash pump speed (rpm) was 60(for 15s), 30 (for 30s) and at the end sample injection pump speed was 30rpm.

\section{Validation and recovery}

The stock solution was diluted to 100,500 , and $1000 \mu \mathrm{g} / \mathrm{L}$ of $\mathrm{Cu}$, Mn, Fe and Zn (Merck, Darmstadt, Germany) to prepare calibration standards. In order to evaluate the analytical performance of method the terms of a calibration curve, coefficient of regression (R2), the Limit of Detection (LOD), the Limit of Quantification (LOQ), and Precision (RSD \%) was calculated. Validation of the analytical method was performed by evaluating the Detection Limit (LOD), Quantitative Limit (LOQ), reproducibility, and reproducibility (accuracy). Matrix effects were studied using standard addition method by adding $200 \mu$ l of standard solutions mixed to the original samples (Mix standard CRM: 92,091 Supelco LOT BCCB9855, Trace CERTR, 33 metals, $10 \mathrm{mgL}^{-1}$ in $\mathrm{HNO}_{3}$, Hg standard CRM:28,941 Supelco, LOT BCCB8927, $1000 \mathrm{mgL}^{-1}, \mathrm{Hg}$ in $\mathrm{HNO}_{3}$ ). Accuracy of the methods was evaluated by analyzing certified reference materials (Table 1).

Table 1: Method validation of the ICP-OES.

\begin{tabular}{|c|c|c|c|c|c|c|}
\hline Metals & Wavelength (nm) & Calibration rang & Calibration rang & LOD $\left(\mu \mathrm{gkg}^{-1}\right)$ & LOQ $\left(\mu \mathrm{gkg}^{-1}\right)$ & $\mathbf{R} 2$ \\
\hline $\mathrm{Cu}$ & 324.754 & $0.1-1200$ & 97 & 0.306 & 0.918 & 0.99998 \\
\hline $\mathrm{Zn}$ & 213.9 & $0.3-1200$ & 101 & 0.27 & 0.81 & 0.9995 \\
\hline $\mathrm{Fe}$ & 259.941 & $0.16-1200$ & 99 & 0.16 & 0.48 & 0.9999 \\
\hline $\mathrm{Mn}$ & 257.61 & $0.3-1200$ & 102 & 0.461 & 1.383 & 0.99987 \\
\hline
\end{tabular}




\section{Statistical analysis}

Quantitative variables were conducted by mean \pm standard deviation using SPSS version 21 software and Kolomogorov-smirnov test was used to determine the parametric or nonparametric of the data. One way ANOVA was used to determine the significance and kruskal-wallis test was used. There is no significant difference in the amount of the metals in collected samples ( $p>0.05)$.

\section{Results and Discussion}

In this study, a matrix is shown in the quantification of trace metals in food samples due to effective dissolution. The major oil is the edible part of the olive fruit (the fat content of our fruit samples was between $10-15 \%$ ) and it was shown that the fat problem is in the simplification of the matrix for further quantification of metals. The limits of detection ranged from 0.16 to $0.46 \mu \mathrm{g} / \mathrm{kg}$, and limit of quantification ranged from 0.48 to $1.38 \mu \mathrm{g} / \mathrm{kg}$, respectively. The recoveries were within $97 \%$ and $102 \%$ for all the studied metals (Table 1). The mean $( \pm \mathrm{SD}$ ) and range of the levels of the $\mathrm{Cu}, \mathrm{Fe}, \mathrm{Mn}$, and $\mathrm{Zn}$ in olives are shown in Table 2.

In industrial and traditional samples, the Fe levels were displayed to be higher than $\mathrm{Cu}, \mathrm{Mn}$, and $\mathrm{Zn}$ metals. The number of others decreased follow by $\mathrm{Zn}, \mathrm{Cu}$, and $\mathrm{Mn}$, respectively. Although the level of trace elements among traditional and industrial olives was different, but not significant. These differences might be associated with olive varieties, element distribution in the soil, maturation and processing method, type of packing, as well as environmental and weather conditions. Fe was the amplest among four metals. The concentration of $\mathrm{Fe}$ in the industrial table olives was determined between $57.50 \pm 3.46$ and $61.11 \pm 5.02 \mathrm{mg} / \mathrm{kg}$, whereas in traditional samples was between $46.5 \pm 0.40$ and $55.7 \pm 0.22 \mathrm{mg} / \mathrm{kg}$.

These results were showed that Fe contents of table olives altered agreeing to maturation and processing method. Sahan et al. [7] and Biricik [12] described that Fe levels in green olive were in the range of $6.0 .73-2.55,3.50-6.67$, and $3.99-10.93 \mathrm{mg} / \mathrm{kg}$, respectively. Also, in another study $2.17-3.80 \mathrm{mg} / \mathrm{kg}$ of Fe level was declared [13]. When their results were compared with our results, Fe concentration in olives was different; however different species and processed olives were examined. Besides, results showed the concentration of metals displayed no important changes in content between the two kinds of the table olives (Figure 1). Thus, the differences in Fe level cause the differences in some parts of the processing methods, brand, and type of packaging. Also, another study declared the use of $\mathrm{NaOH}$ may decrease the mineral concentration in olives that are a routine way in traditional olives for removing the bitter taste. Also, chemicals such as iron gluconate (II) or iron lactate (II) are added to stabilize the black color of the olive. Also, based on the results of other studies, production conditions and various characteristics such as maturity affect the amount of iron in olives [7].

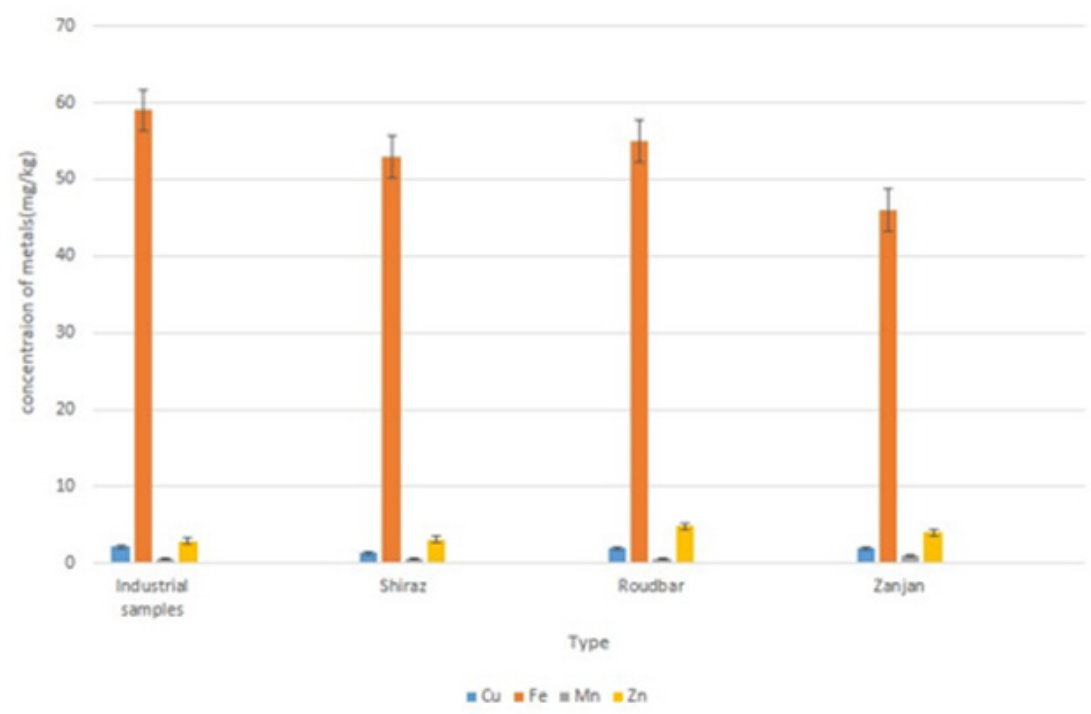

Figure 1: Total metal concentrations $(\mathrm{mg} / \mathrm{kg})$ in olives, considering two types of presentations (traditional and industrial).

The levels of $\mathrm{Cu}, \mathrm{Mn}$, and $\mathrm{Zn}$ were approximately similar in traditional and industrial table olive samples. Besides, no significant differences in these metal levels were found between samples $(\mathrm{p}>0.05)$. The elements $\mathrm{Fe}, \mathrm{Zn}$, and $\mathrm{Cu}$ are essential in human nutrition and were therefore quantified in olives. As shown in Table 2, the average $\mathrm{Zn}$ content of olive samples is between 2.1 and $4.8 \mathrm{mg} / \mathrm{kg}$ and may depend on the variety, maturation period, and origin of the fruit is variable. Several studies have controlled $\mathrm{Zn}$ levels in olives. The content of Mn assessed samples are shown in Table 2. The mean Mn values belonging to the Zanjan type were found to be $0.9 \pm 0.35 \mathrm{mg} / \mathrm{kg}$. In statistical evaluation, it was shown that the not significant differences $(p>0.05)$ among these types with other samples. These little differences might be the variety, origin of the fruit and may also differently processing methods. 
Table 2: The nutritional metals concentrations in olive collected $\left(\mu \mathrm{gkg}^{-1}\right)$.

\begin{tabular}{|c|c|c|c|c|c|}
\hline \multirow{2}{*}{ Canned black olive } & \multirow{2}{*}{$\mathbf{N}$} & \multicolumn{4}{|c|}{ Elements } \\
\hline & & $\mathrm{Cu}$ & $\mathrm{Fe}$ & Mn & Zn \\
\hline Commercial samples & 24 & $2.1 \pm 0.3$ & $59.2 \pm 14$ & $0.5 \pm 0.3$ & $2.9 \pm 0.1$ \\
\hline Shiraz & 8 & $1.3 \pm 0.6$ & $53.1 \pm 17$ & $0.5 \pm 0.07$ & $3.1 \pm 1.3$ \\
\hline Roudbar & 24 & $1.9 \pm 0.8$ & $55.7 \pm 22$ & $0.6 \pm 0.2$ & $4.8 \pm 2.2$ \\
\hline Zanjan & 8 & $1.9 \pm 0.6$ & $46.5 \pm 40$ & $0.9 \pm 0.35$ & $4.0 \pm 1.9$ \\
\hline
\end{tabular}

$\mathrm{Cu}$ metal is important for fighting fungal diseases of olive trees due to the fungicidal formulations containing this element. The role of $\mathrm{Cu}$ as a transition metal is also important because it acts as a very strong oxidation catalyst even at low concentrations. The high content of oil in the olive fruit has a high probability of accumulation of this metal in it, so the residues of this metal were controlled to determine their effect on the final quality of the product. All 12 samples had $\mathrm{Cu}$ concentrations below $6 \mathrm{mg} / \mathrm{kg}$, therefore there was no problem with the standard [7]. Zeiner et al. [14] have shown that concentrations of $\mathrm{Ca}, \mathrm{Fe}, \mathrm{Mg}, \mathrm{Na}$, and $\mathrm{Zn} \mathrm{3.95,} \mathrm{15.31,} \mathrm{3.26,} \mathrm{33.10,}$ and $3.39 \mu \mathrm{g} / \mathrm{g}$, respectively [14]. Hernandez et al. [15] indicated that concentrations of Mg, Zn, Cu, and Fe 0.052,0.080,0.095, and 0.305mg/ $\mathrm{kg}$, respectively [15]. Sahan et al. [7] reported that concentrations

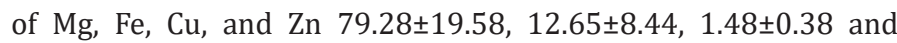
$8.50 \pm 1.74 \mathrm{mg} / \mathrm{kg}$, respectively in Black olives and $37.64 \pm 13.14$, $7.08 \pm 1.56,0.78 \pm 0.20$ and $10.58 \pm 2.01 \mathrm{mg} / \mathrm{kg}$, respectively in green olives [7]. Acar et al. [13] shown that concentrations of $\mathrm{Cu}, \mathrm{Fe}$, and Zn $3.26 \pm 0.37,16.3 \pm 1.6$ and $3.86 \pm 0.38 \mathrm{mg} / \mathrm{kg}$, respectively in Black olives and $2.55 \pm 0.28,15.2 \pm 1.2$ and $4.12 \pm 0.29 \mathrm{mg} / \mathrm{kg}$ in green olives, respectively [13]. The metal content of olives can also change for other different reasons. Metals can be present in olive fruits in two ways, endogenously or exogenously, depending on the mineral composition of the soils in which the olive trees are located in the latter case due to air pollution, pollution by chemical products, and technological processing $[7,8]$. In particular the high content of lipids in olive fruit, there is a possibility of accumulation of metal residues and therefore should be measured to control their effect on the final quality of the olives [2].

\section{Conclusion}

Consumption of table olives is high in Iran; thus, its consumption can be effective in the overall absorption of these nutritious and even heavy metals. The results of this study show that the amount of olive consumption in the diet in the average level of various metals is mainly below the safety limit for table olives. Therefore, it can be concluded that the surface of the 4 metals studied is in the safety range. The data obtained in this study will be very valuable in supplementing the data on heavy metals in the national standard of Iran. The metals magnesium, iron, zinc, and copper are significant. In the content between the two types of traditional and industrial table olives. Factors such as processing method, brand, and packaging materials can affect the metal content of the final product. To examine this difference in detail, new studies on the impact of different soil composition species can be considered.

\section{References}

1. Crisosto C, Ferguson L, Nanos G (2011) Olive (Olea europaea L.) postharvest biology and technology of tropical and subtropical fruits. (1 ${ }^{\text {st }}$ edn), Elsevier, Netherlands, pp. 63-87.

2. Kiritsakis A, Markakis P (1988) Olive oil: a review. Advances in food Research 31: 453-482.

3. Boskou D (2017) Table olives: A vehicle for the delivery of bioactive compounds. Journal Exp Food Chemistry 3(1): 1000123.

4. Piga A, Gambella F, Vacca V, Agabbio MCS (2001) Response of three sardinian olive cultivars to Greek-style processing. Italian Journal of Food Science 13(1): 29-40.

5. Sharifi TA, Roudsari LP, Aghaee EM, Nazmara S, Sadighara P, et al. (2020) Measurement of iron content and detection of sulfate ion in traditional/ industrial canned black olives in Iran. Current Nutrition \& Food Science 16(7): 1112-1118.

6. Tassou C, Panagou E, Katsaboxakis K (2002) Microbiological and physicochemical changes of naturally black olives fermented at different temperatures and $\mathrm{NaCl}$ levels in the brines. Food microbiology 19(6): 605-615.

7. Şahan Y, Basoglu F, Gücer S (2007) ICP-MS analysis of a series of metals (Namely: $\mathrm{Mg}, \mathrm{Cr}, \mathrm{Co}, \mathrm{Ni}, \mathrm{Fe}, \mathrm{Cu}, \mathrm{Zn}, \mathrm{Sn}, \mathrm{Cd}$ and $\mathrm{Pb}$ ) in black and green olive samples from Bursa, Turkey. Food Chemistry 105(1): 395-399.

8. Arias CA, Bubba M, Brix H (2001) Phosphorus removal by sands for use as media in subsurface flow constructed reed beds. Water Research 35(5): 1159-1168.

9. Menaie H, Ragam O, Mahgoub H, Hadidi M, Shatti A, et al. (2014) Evaluation of some olive cultivars under Kuwait environmental conditions. Olivebioteq p. 45.

10. Rico L, Perez J, Marini ME (2007) Content and daily intake of copper, zinc, lead, cadmium, and mercury from dietary supplements in Mexico. Food and chemical toxicology 45(9): 1599-1605.

11. Altundag H, Tuzen M (2011) Comparison of dry, wet and microwave digestion methods for the multi element determination in some dried fruit samples by ICP-OES. Food and Chemical Toxicology 49(11): 28002807.

12. Biricik GF, Basoglu F (2006) Determination of mineral contents in some olives (Samanl, Domat, Manzanilla, Ascolana) varieties. Gida (2): 67-75.

13. Acar O (2012) Evaluation of cadmium, lead, copper, iron and zinc in Turkish dietary vegetable oils and olives using electrothermal and flame atomic absorption spectrometry. grasas y aceites 63(4): 383-393.

14.Zeiner M, Steffan I, Cindric IJ (2005) Determination of trace elements in olive oil by ICP-AES and ETA-AAS: A pilot study on the geographical characterization. Microchemical Journal 81(2): 171-176.

15. Hernández AF, Mateos R, Mesa JAG, Beltran G, Escobar RF (2010) Determination of mineral elements in fresh olive fruits by flame atomic spectrometry. Spanish Journal of Agricultural Research 8(4):1183-1190.

For possible submissions Click below: 